\title{
Electrochemical Properties of Carbon Composites Prepared by Using Graphite Ball-milled in Argon and Air Atmosphere
}

\author{
Kyoung-Muk Lee, Seh-Min Oh, ${ }^{\dagger}$ and Sung-Man Lee \\ Deparment of thanced Materials Science and Engineering, Kangwon Vational Lniversitw, Chincheon, \\ Kangwon 200-701, Korea. "E-mail: smlee akangwonac.kr \\ ${ }^{\dagger}$ Carbonix, Inc., 938-3, Taegok-ri, Buk-myeon, Jeongeup, Jeonbuk 580-812, Korea \\ Received January 24, 2008
}

\begin{abstract}
A carbon composite was synthesized by mechanical mixing of ball-milled graphite and PVC powders. followed by py rolysis reaction of PVC. Natural graphite ball milled under atmosphere of argon or air leads to a disordered structure. It appears that the electrochemical lithium intercalation reaction is dependent on the atmosphere in which the graphite is ball milled. The carbon composite obtained using air-milled graphite shows a high reversible capacity and high initial coulombic efficiency compared to argon-milled graphite. This is attributed to the enhanced thermal stability of a disordered stnucture in the air milled sample. For the one with air-milled graphite. the disordered stnicture is maintained during heat treatment. while argon-milled graphite is partially crystallized.
\end{abstract}

Key Words : Graphite. Ball-milling, Electrochemical performance, Lithium-ion battery

\section{Introduction}

Carbonaceous materials are continue to be very attractive anode materials for lithium-ion batteries. As they are available in various structures and morphologies. they show different electrochemical performances. For highly crystalline graphite. the lithium storage capacity is limited to a theoretical value of $372 \mathrm{mAl} / \mathrm{g}$. However it is known that disordered carbonaceous materials can offer high capacities beyrond $372 \mathrm{mAl} / \mathrm{g} \cdot{ }^{1-6} \mathrm{~A}$ lot of studies have been performed to produce disordered carbonaceous materials with high capacities. Mechanical milling of graphite is one possibility of producing such disordered carbons. ${ }^{7-12}$ However. ballmilled graphites exhibit a large irreversible capacity loss during the first charge (intercalation) due to their large specific surface areas. ${ }^{7-\overline{4}}$ To solve the problem. encapsulating the ball-milled graphite particles with a soft carbon is an effective method making them less susceptible to irreversible reactions. On the other hand. the structure and properties of ball-milled graphite is significantly influenced by the atmosphere during ball-milling. ${ }^{\text {13-15 }}$

In this work. therefore. we have synthesized the carbon composites by pelletizing graphites ball-milled under two different atmospheres of argon and air using polyvinyl chloride (PVC), and examined their electrochemical performances as anode for lithium ion batteries.

\section{Experimental}

Natural graphite was milled in a planetary ball-mill (pulverisette 7) for $15 \mathrm{~h}$ under atmosphere of argon or air with steel milling tools. The weight of ball to graphite powder was 10. Carbon composites were prepared by mechanically mixing the ball-milled graphite with PVC as a soft carbon precursor. followed by heating the mixture in an alumina boat at $1000-1200^{\circ} \mathrm{C}$ for $\mathrm{l} \mathrm{h}$ in an argon flow. The resultant composites contain the PVC carbon of $30 \mathrm{wt} . \%$. After each ball milling experiment, in order to examine the process occurring during subsequent annealing some milled powders were annealed in a flow of argon gas prior to carbon composite. The structural properties of as-milled post-annealed. and carbon composite powders were examined by $\mathrm{X}$-ray diffraction (XRD) with $\mathrm{Cu} \mathrm{K} \mathrm{K}_{a}$ radiation. The powder morphology was studied by scanning electron microscopy (SEM). The electrochemical properties were measured using coin-type cells (CR 2016) consisting of a lithium foil counter electrode and a working electrode. The working electrode was made by pasting a slurry of $95 \mathrm{wt} \%$ active material and 2.5 wt.\% styrene butadiene rubber (SBR) dissolved in 2.5 wt. \% carboxy methyl cellulose (CMC) water solution. onto a copper foil and drying in vacuum at $180^{\circ} \mathrm{C}$ for $12 \mathrm{~h}$. The electroly te was $1 \mathrm{M} \mathrm{LiPF}_{6}$ in a mixture of etlyy lene carbonate (EC) and diethyl carbonate (DEC) (1:1 by volume). The coin cells were assembled in an argon-filled glove box. The cells were charged (intercalated) in a constant current-constant voltage (CC-CV) mode consisting of constant current at $0.2 \mathrm{~mA} / \mathrm{cm}^{2}$ followed by constant-voltage at $0.005 \mathrm{~V}$ until the current tapered down to $0.01 \mathrm{~mA}$ and discharged (deintercalated) at a constant-current of $0.2 \mathrm{~mA} / \mathrm{cm}^{2}$.

\section{Results and Discussion}

The SEM micrographs for as-received graphite. ballmilled graphite samples and carbon composites are shown in Figure 1. The raw graphite particles have a flaky appearance with an average size of about $5 / \mathrm{m}$. After ball-milling. the particles agglomerated. This agglomerate consists of mainly fine particles of less than $1 / \mathrm{m}$ as presented in Figure 2 .

Figure 3 shows the XRD patterns of the graphite ballmilled under argon and air atmosphere and the samples post- 
annealed in argon. The XRD pattern of raw graphite is presented for comparison. Independent of the milling atmosphere, the broad peak of ball-nulled samples indicates that natural graphite was converted into a disordered structure by mechanical milling. The extra peaks. produced by contamlnation from steel vial and balls during milling. appear. resulting in the formation of iron carbide $\left(\mathrm{Fe}_{3} \mathrm{C}\right.$ ) on subsequent anuealing of the ball-nilled samples. These characteristics related to ball-nilled graphites have been previously reported. $^{7.1^{2}}$ A noticeable feature noted from the XRD patterns in Figure 3(b) and (c) is that in the case of argon milled sample the (002) diffraction peak of graphite recovers after annealing at temperatures above $1000^{\circ} \mathrm{C}$, while for air milled graphite, the XRD profile near the $(002)$ peak position of graphite appears to be similar before and after annealung. This means that the disordered structure of ballmilled graphite is more stabilized by milling under air atmosphere than under argon. It has been reported that the oxygen reacted and bonded to the graphite when the millung
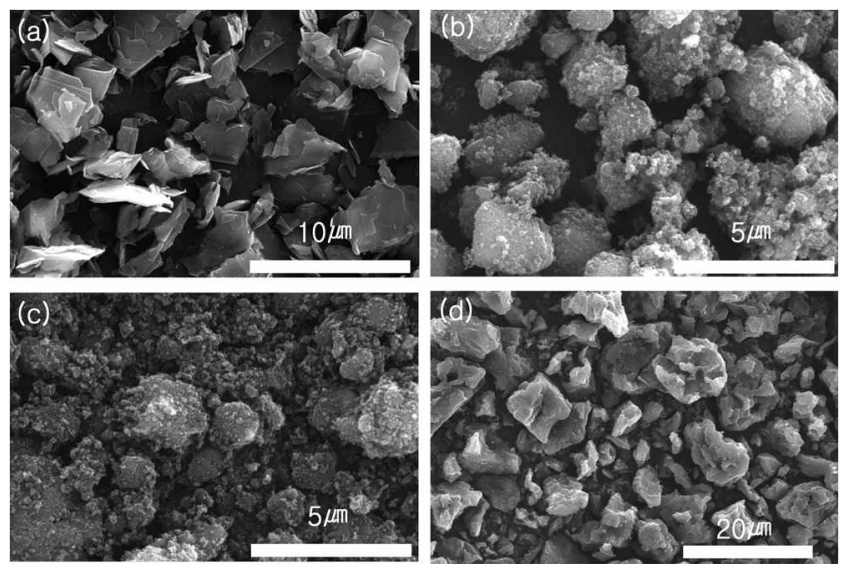

Figure 1. SEM micrographs of (a) as-received natural graphite, (b) ball-milled graphte under argon, (c) ball-milled graphite under air and (d) carbon composites.
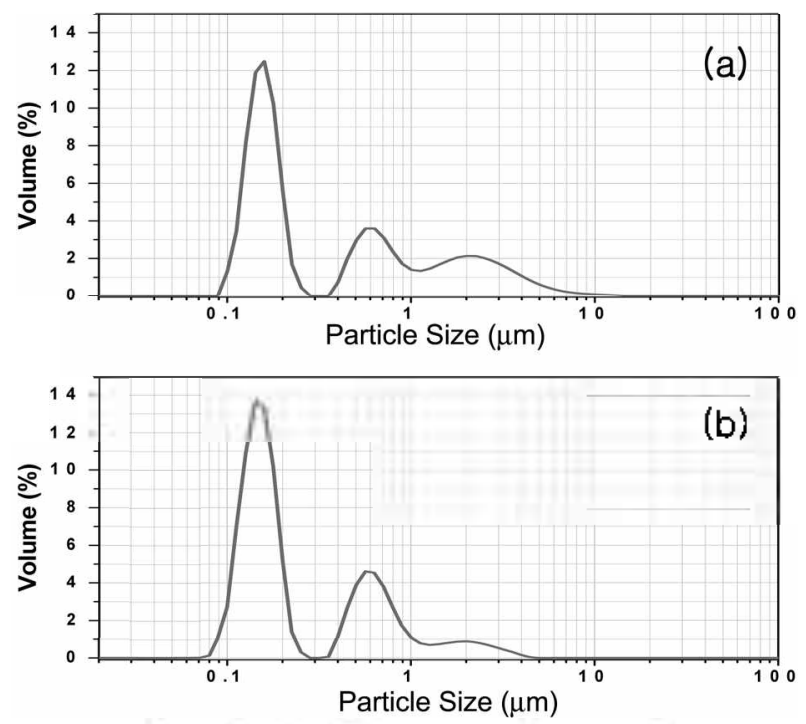

Figure 2. Particle size distribution of graphite ball-milled under (a) argon and (b) air. was performed under air or oxygen. in which an oxygen atom can act as cross-link between the carbon edges of the graphene layers and the dangling bonds fomed at the boundaries of the broken graphene layers. ${ }^{13.14}$ Such oxygens in the disordered smaple should be evolved pnor to graplutization during annealing. which requires a lugh activation energy. Therefore, it is believed that this suppresses the crystallization in air-milled sample as shown in Figure 3(c). This is supported by the results of chemical analysis on the composite sanples heated to 1200 (See Table 1), in which the composite made from aur-milled graphite contains a little more amount of oxygen and nitrogen than the sample with argon-milled graphite.

Figure 4 shows the XRD patterns of carbon composites, prepared by mixing the ball-milled graphite with PVC. powders. followed by heat treatment at 1200 under a flow of
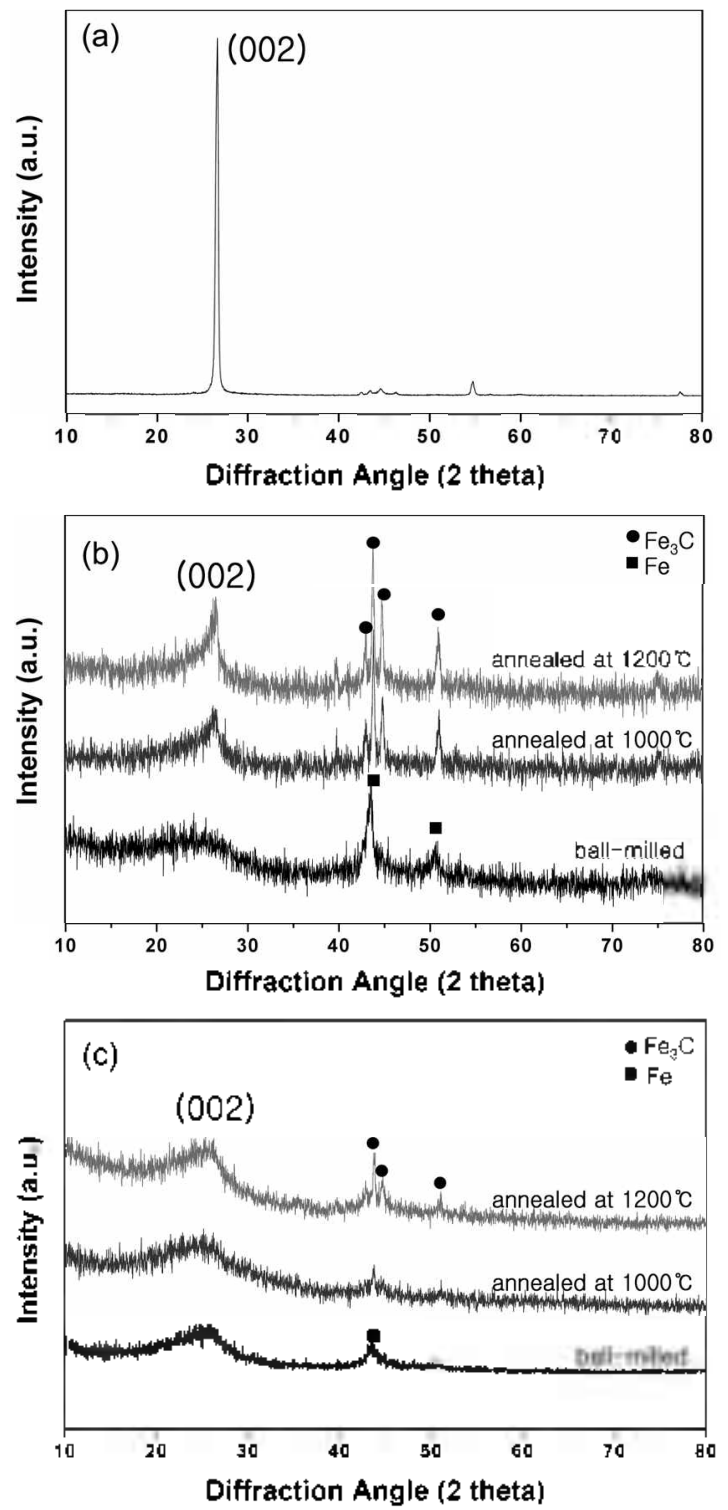

Figure 3. XRD pattens of (a) as-received natural graphite, (b) argon-milled graphte and post-annealed samples. (c) arr-milled graphite and the post-annealed samples. The post-annealung was performed un argon. 
Table 1. Elemental analysis of the composite samples heated to 1200

\begin{tabular}{cccc}
\hline $\begin{array}{c}\text { Ball-milling } \\
\text { atmosphere }\end{array}$ & $\mathrm{N} / \mathrm{C}^{\sigma}$ & $\mathrm{H} / \mathrm{C}^{b}$ & $\mathrm{O} / \mathrm{C}^{c}$ \\
\hline air & 0.002 & 0.0009 & 0.0072 \\
argon & - & 0.0004 & 0.0056 \\
\hline
\end{tabular}

"NC: nitrogen-carbon atomic ratio. "HC: hydrogen-carbon atomic ratio. ${ }^{\circ} \mathrm{C}:$ osygen-carbon atomic ratio

argon gas. It appears that the composite obtained from the Ar-milled graphite includes crystallized particles as inferred from the fact that the $(002)$ diffraction peak of graphite recovers after heat treatment. while the XRD profile of the composite composed of air-milled graphite still shows a broad peak. This is expected from the results of Figure 3.

Figure 5 shows the charge (intercalation)-discharge (deintercalation) curves for the first and second cycles of the carbon composite electrodes. The potential profile of the composite electrodes is similar to that of typical disordered carbons in which the potential changes gradually without showing a plateau region as in graphite. It is noticeable that a large potential hysteresis for ball milled graphite samples. as shown in Figure 6 is significantly reduced in the carbon composites. These behaviors seem to be independent of whether the composite is composed of argon-milled graphite or air-milled sample. However, the potential plateau near 0.8 $V$, ascribed to electrolyte decomposition on the surface of graphite. appears during the first charge of the conposite with argon-milled graphite. This is consistent with the XRD results of Figure 3 and 4 , in which the disordered sample obtained by ball milling in argon is partially crystallized during subsequent annealing at $1200^{\circ} \mathrm{C}$.

It is believed that the composite with argon-milled graphite consists of nanocrystalline graphite embedded in pyrocarbon matrix (PVC carbon) as inferred from the XRD results of Figure 3 and 4. It is also clear that the composite with air-milled graphite shows higher reversible capacity and lower initial capacity loss compared with the composite with argon-milled graphite. The low capacity and coulombic

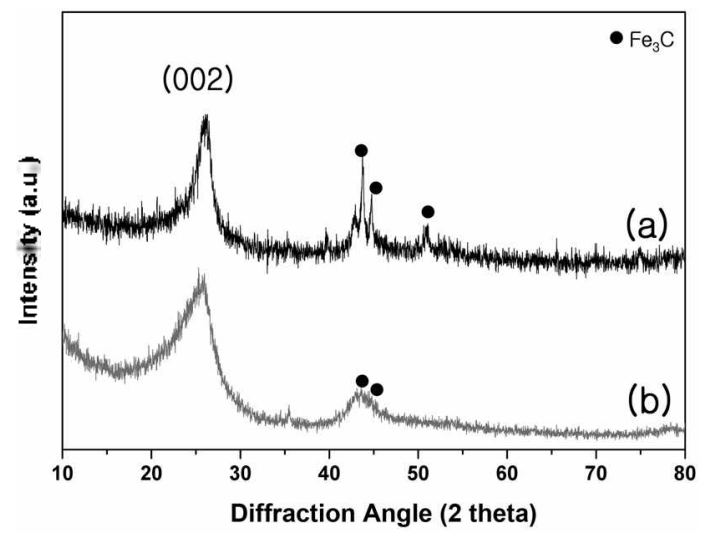

Figure 4. XRD pattens of carbon composites, prepared by mixng the ball-milled graphite with PVC powders, followed by heat treatment at 1200 " $\mathrm{C}$ : (a) with graphite ball-milled in argon (b) with graphite ball-milled in air. efficiency of the composite with argon-milled graphite are probably associated with the crystallization of ball-milled graphite during heat treatment for pyrolysis reaction of PVC. Considering that the large reversible capacities of highly ballmilled graphites (disordered carbons) are due to lithium being stored in microvoids. microcavities and active surface sites introduced by ball milling. ${ }^{7.9}$ it is assumed that such defects would be reduced as a result of crystallization of ballmilled graphites, which leads to a reduced reversible capacity for the composite with argon-milled graphite as
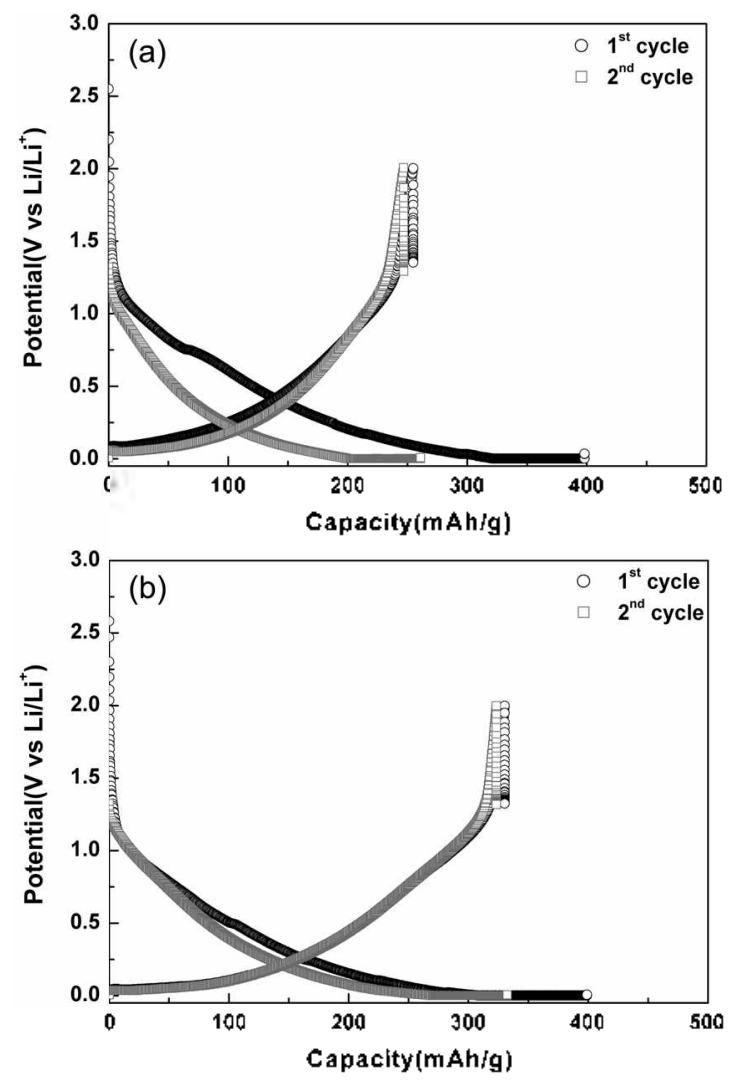

Figure 5. Charge - discharge curves for the first and second cycles of the carbon composite electrodes, prepared by mixing the ball milled graphite with PVC powders and then heating at $1200^{\circ} \mathrm{C}$ : (a) with argon-milled graphite and (b) with air-milled graphite.

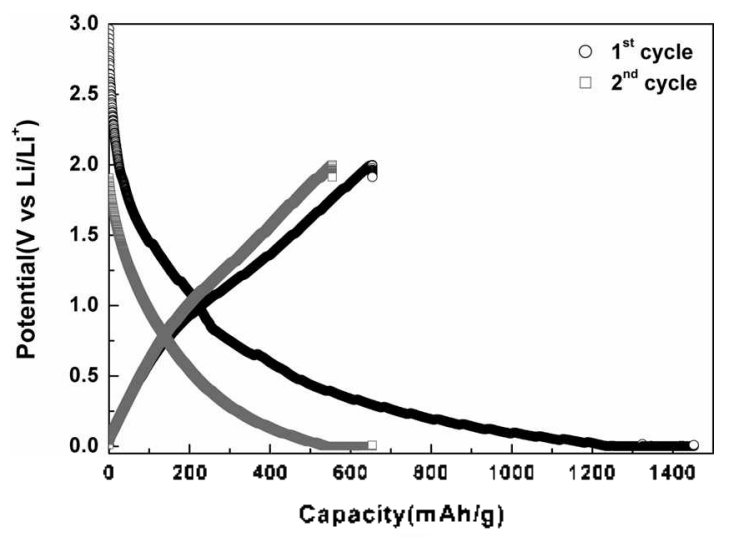

Figure 6. Charge-discharge curves for the first and second cycles of the graphite ball-milled under air. 


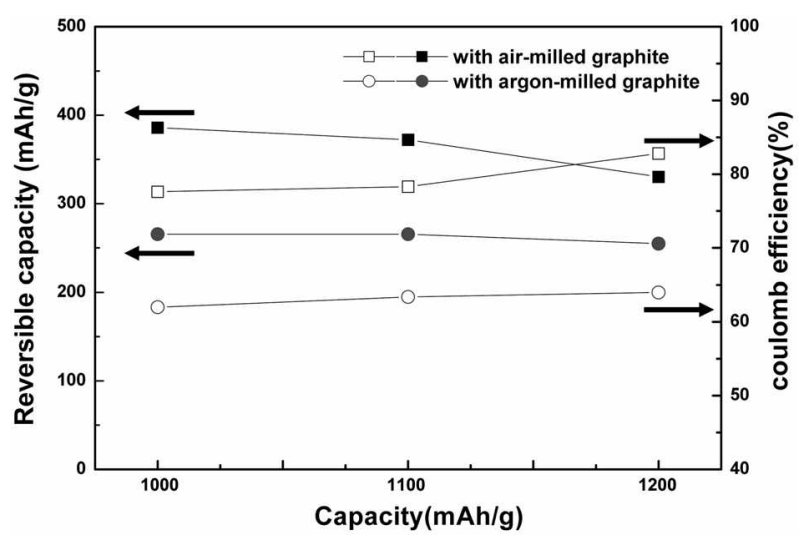

Figure 7. Reversible capacity and initial coulombic efticiency of the composite electrodes as a function of the heat treatment temperature.

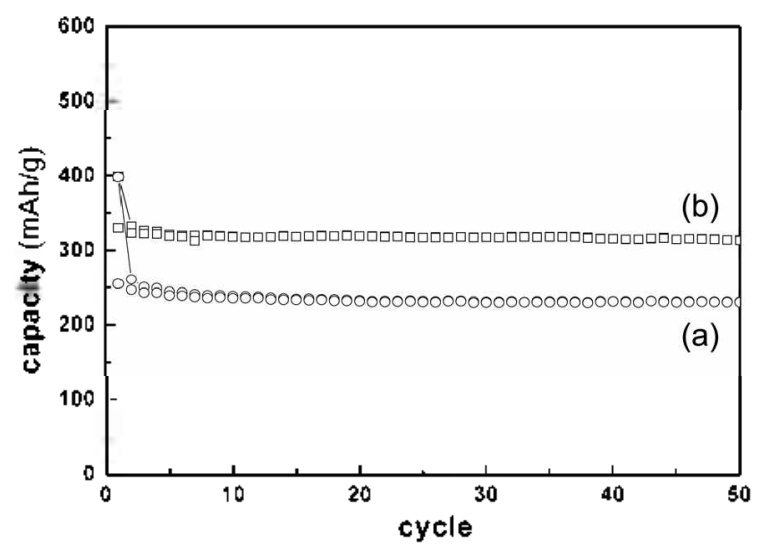

Figure 8. Cycling perfonmance of carbon composites, prepared by mixing the ball-milled graphite with PVC powders, tollowed by heat treatment at $1200^{\circ} \mathrm{C}$ : (a) with argon-milled graphite and (b) with air-milled graphite.

shown in Figure 5. Moreover, the graphitization increases the active edge planes. susceptible to the irreversible reactions. On the other hand. the composite with air-milled graphite maintains the disordered structure caused by ballmilling. which leads to high reversible capacity and low irreversible capacity loss compared with the composite with argon milled graphite

The reversible capacity and the initial coulombic efficiency of the composite electrodes are dependent on the heat treatment temperature for composite fabrication as shown in Figure 6. respectively. The coulombic efficiency slightly increased with increasing heat treatment temperature up to $1200^{\circ} \mathrm{C}$. Interestingly, the composite with air-nilled graphite exhibits the largely reduced reversible capacity when heat treated at $1200^{\circ} \mathrm{C}$. This is attributable to the evolution of air components like oxygen and nitrogen which contributed to maintain the disordered structure of air-milled graphite. Figure 7 shows the variation of reversible capacity with cycle number for the composites obtained by heating at 1200
${ }^{\circ} \mathrm{C}$. Both composite electrodes are very stable on cycling. although the composite with air-milled graphite can deliver higher reversible lithium storage capacity than the composite with argon-milled graphite.

In summary, the electrochemical properties of the carbon composite. prepared by using ball-milled graphite. are significantly influenced by the milling atmosphere during ball-milling.

\section{Conclusion}

A carbon composite was synthesized by mechanical mixing of ball-milled graphite and PVC powders. followed by pyrolysis reaction in argon atmosphere. The ball-milling of graphite was performed in two different atmospheres of argon and air. The resultant ball-milled graphites exhibit a disordered state as determined by XRD method. The electrochemical performances of the carbon composite with respect to lithium intercalation are strongly dependent on the atmosphere in which graphite is milled. The composite with air-milled graphite exhibits higher reversible capacity and lower initial irreversible capacity loss than the composite prepared using argon-milled graphite. This is attributed to the enhanced themal stability of a disordered structure in air-milled graphite.

Acknowledgements. This work was supported by the Division of Advanced Batteries in NGE Program (Project No. $=10016446$ ).

\section{References}

1. Sato. K.: Noguchi. M.: Demachi. A.: Oki. N.: Endo. M. Science 1994. 264.556 .

2. Zheng. T.: Liu. Y.: Fuller. E. W.: Tseng. S.: Vontsacken. U.: Dahn1. J. R. J. Electrochem. Soc. 1995, 142.2581

3. Dahn. J. R.; Zheng. T.; Liu. Y.: Xue. J. S. Science 1995, 270. 590

4. Inaba. M: Yoshido. H.: Ogumi, Z. J. Electrochem. Soc. 1996. I+3.2572.

5. Kim. W. S.: Hark. D. W.: Jung. H. J.: Choi. Y. K. Bull. Korean Chent Soc. 2006. 27. 82 .

6. Mabuchi. A.; Tokumitsu. K.; Fujimoto, H.: Kasulh. T. d. Electrochem. Soc. $1995,1+2,1041$

7. Disma. F.: Aymard, L.; Dupont. L.: Tarascon. J.-M. J. Electrochem. Soc. 1996. 143. 3959 .

8. Wang. C. S.: Wu. G. T.: Li. W. Z. J. Poner Sontes 1998. 76. 1.

9. Ong. T. S.: Yang. H. J. Electrochent Soc. 2012. 1+9. Al.

10. Huang. J. Y. Acta later: $1999,+7,1801$.

11. Wakayama. H.: Mizuno. J.: Fukushima, Y: Nagano, K; Fukunaga. T.: Mizutani. U. Carbon 1999. 37, 947.

12. Salver-Disma. F.: Hasguier. A. D.: Tarascon1. T.-M.: Lassegues. J.C.: Rouzaud. J.-N. J. Power Sontecs 1999. 81-82. 291.

13. Francke. M.: Hermann. H.: Wenzel. R.: Seifert. G.: Wetzig. K Carbon 2005. 43. 1204.

14. Ong. T. S.; Yang. H. Carbon 2000. 38, 2077

15. Chevallier, F; Aymard. L.: Tarascon, J.-M. d. Electrochem. Soc. 2001. 148. A1216. 